\title{
Perfil Da Gestão Financeira Das Empresas Industriais Atendidas Pelo Peiex Núcleo São Paulo/SP Entre 2010 - 2012
}

\section{Profile Of Financial Management In Industrial Companies Served By Core Peiex São Paulo / SP Between 2010-2012.}

Jose Flavio Messias ${ }^{1}$, José Ultemar da Silva², Alessandro Marco Rossini ${ }^{3}$

\begin{abstract}
1. Doutor Ciências Sociais / Relações Internacionais - PUC/SP. Professor da Faculdade Eniac /Guarulhos/SP - E-mail: jflaviomessias@hotmail.com

2. Pós-Doutor em Administração / USP. Doutor em Ciências Sociais / Relações Internacionais - PUC/SP. Professor da Pós Graduação da UNIP/SP.

3. Pós-Doutor em Administração / USP. Doutor em Ciências Sociais - PUC/SP. Professor do Curso de Mestrado em Administração Empresas - FMU/SP.
\end{abstract}

Resumo

O presente artigo é uma pesquisa aplicada com base documental com focos nas micro, pequenas e médias empresas - PME’S, atendidas pelo Projeto de Extensão Industrial Exportadora - PEIEX, da APEX Brasil em parceria com o Núcleo de Negócios Afro-Étnicos Zumbi dos Palmares, Núcleo Operacional - SP. Neste sentido, procurou-se identificar a adoção de técnicas de planejamento financeiro e da utilização dos controles financeiros como instrumento de gestão financeira nas empresas. Utilizamos as informações obtidas na aplicação dos questionários aplicados no Projeto PEIEX às empresas participantes, procurando identificar a importância atribuída por elas aos controles financeiros e analisar os reflexos desencadeados nos demais setores da empresa.

Palavras-Chave: Projeto PEIEX, diagnóstico PME’s, Gestão Financeira, Planejamento Financeiro, Capacitação.

\section{Abstract}

This article is an applied research with documentary base focused on micro, small and medium sized industrial firms serviced by the industrial Export Extension Project-PEIEX of APEX Bragil in partnership with the Afro-Ethnic business Core Zumbi dos Palmares, Operational Core - SP. In this sense, we tried to identify the adoption of financial planning techniques and the use of financial controls as an instrument of financial management in enterprises. We use the information obtained 
in the application of questionnaires applied in PEIEX Project to the participating companies, seeking to identify the importance attributed by them to financial controls and analyze the reflection triggered in other sectors of the company.

Keywords: Project PEIEX, diagnosis SMEs, Financial Management, Financial Planning, Training.

\section{Introdução}

O momento atual caracteriza-se pela intensificação das relações sociais e econômicas, dos fluxos comerciais e de capitais em escala mundial, estabelecendo uma padronização de produtos e de comportamento. Alicerçada pela rápida evolução tecnológica (informática, internet, redes sociais, robótica, mecatrônica, etc...) este processo aumenta drasticamente os níveis de produtividade e estabelece um nível de concorrência global.

Independente do porte da empresa, ela é diretamente influenciada por este processo de internacionalização das economias: pulverização da produção, integração da gestão das empresas multinacionais, melhoria contínua dos produtos / processos, pressão pela redução de custos e ampliação das margens de lucro. Particularmente no caso brasileiro, em função da infraestrutura incipiente e carga fiscal elevada, acaba acarretando elevados custos de produção, agravam ainda mais a situação, principalmente para as empresas micro, pequenas e médias (PME's).
Segundo Lucato e Vieira Jr. (2006) na gestão das empresas micro, pequenas e médias (PME's) existe uma enorme confusão entre propriedade e gestão, na relação entre os valores pagos a título de pró-labore e a distribuição de dividendos assim como na mistura entre as finanças pessoais dos sócios com as das suas respectivas empresas.

Outro ponto discutido pelos autores é que os empreendedores não consideram as informações contábeis como auxiliares no seu processo de tomada de decisões, confiando apenas na sua intuição. A contabilidade é vista pelos proprietários-gestores das PME's como um mal necessário para atender às exigências das autoridades fiscais e tributárias. $\mathrm{Na}$ pesquisa realizada por Lucato e Vieira Jr. (2006) em relação a algumas PME's selecionadas, de uma forma geral, a gestão era realizada exclusivamente com base no conhecimento dos saldos bancários, sem levar em conta as informações mostradas nos respectivos demonstrativos contábeis e sem conhecer, portanto, o montante de lucro ou de prejuízo gerado pelas operações da empresa.

Os controles financeiros representados pelo Orçamento empresarial, o Fluxo de Caixa, o Demonstrativo do Resultado do Exercício 
(DRE), entre outros, a mensuração adequada dos custos e a formação de preços são fundamentais para a análise da situação que a empresa se encontra, não só financeiramente, mas em termos de produção, vendas, estoque, e a própria viabilidade do negócio.

A falta de coordenação e de planejamento entre todas as áreas da empresa: compras, produção, vendas, controle de estoque, formação de preços, contas a pagar e a receber, gera um descompasso no fluxo de recursos da empresa. Existe sobra de recursos em determinados momentos, falta em outros, de forma que boa parte da lucratividade é absorvida pelos custos financeiros decorrentes de captação de recursos no mercado financeiro.

A Administração Financeira em si não é responsável pelo sucesso das empresas. No entanto, o planejamento das atividades e consequentemente a maximização de todos os recursos envolvidos, proporciona maior segurança para o empresário na tomada de decisão e garante maior rentabilidade ao negócio, agregando valor à empresa.

Todas as áreas da empresa, como marketing, produção e recursos humanos estão intimamente ligadas à área de finanças, pois sem capital para atender as necessidades da empresa, seja para financiar o seu crescimento ou para atender as operações do dia a dia, não podemos desenvolver e testar novos produtos, criar ações de marketing, comprar matéria prima, etc.
O papel do gestor financeiro é justamente assegurar que esse capital esteja disponível nos montantes e no momento adequado e ao menor custo, caso contrário à empresa não sobreviverá (Matias e Lopes Jr., 2002).

Este artigo tem como objetivo geral avaliar como é realizada a administração financeira das empresas atendidas pelo Projeto Extensão Industrial Exportadora - PEIEX, Núcleo São Paulo/SP, mais especificamente na mensuração adequada das receitas e despesas relacionadas ao funcionamento da empresa e na adoção do fluxo de caixa como instrumento de gestão e tomada de decisões.

\section{Premissas do Projeto PEIEX}

O PEIEx é um sistema de resolução de problemas técnico-gerenciais e tecnológicos que visa incrementar a competitividade e promover a cultura exportadora empresarial e estrutural em Arranjos Produtivos Locais (APL's) selecionados. O projeto foi desenvolvido Agência Brasileira de Promoção de Exportações e Investimentos - APEX-Brasil, vinculada ao Ministério de Desenvolvimento Indústria e Comércio Exterior (MDIC). Entre seus objetivos específicos, temos (PEIEX, Manual de Trabalho, 2011):

- Incrementar a competitividade das empresas

- Disseminar a cultura exportadora; 
- Ampliar o acesso serviços de apoio nas instituições de Governo e setor privado;

- Introduzir melhorias técnico-gerenciais e tecnológicas;

- Contribuir para a elevação do nível de emprego e de renda;

- $\quad$ Promover a capacitação para a inovação;

- Promover a interação e a cooperação entre as empresas e instituições de apoio.

O Projeto de Extensão Industrial Exportadora - PEIEX, da APEX Brasil em parceria com o Núcleo de Negócios AfroÉtnicos Zumbi dos Palmares, Núcleo Operacional - SP atendeu 140 empresas de diversos segmentos produtivos industriais, com a seguinte composição por número de funcionários (classificação MDIC): 71\% (1 - 19), $22 \%$ (20-99), $6 \%$ (100-199) e $1 \%$ acima de 500 funcionários, num período de 16 meses, entre 2010 e 2012.

A proposta do projeto é realizar um Diagnóstico de cada área funcional (Administração Estratégica, Capital Humano, Finanças e Custos, Vendas e Marketing, Comércio Exterior e Produto e Manufatura). Os dados e informações servirão como indicadores básicos para apontar as principais forças, fraquezas, oportunidades e ameaças que interagem no contexto competitivo da empresa. Posteriormente, são oferecidas orientações e capacitações para melhoria dos processos e da gestão, através da própria equipe ou instituições de apoio públicas ou privadas (PEIEX, Manual de Trabalho, 2011).

\section{Fundamentação Teórica}

Em se tratando de um artigo que procura avaliar o perfil da gestão financeira adotado nas empresas selecionadas, fez-se necessária uma discussão teórica, onde se busca confrontar os pensamentos dos diversos autores frente aos processos gerenciais dessas organizações.

As Finanças podem ser definidas como a arte e a ciência do gerenciamento dos recursos disponíveis. Virtualmente, todos os indivíduos e organizações ganham ou captam e gastam ou investem dinheiro. As finanças lidam com o processo, as instituições, os mercados e os instrumentos envolvidos na transferência de dinheiro entre indivíduos, negócios e governos (GITMAN, 2001).

No ambiente empresarial, a administração financeira está focada nas seguintes funções: planejamento financeiro, controle financeiro, administração de ativos e administração de passivos. Com base nestas funções, independente da atividade operacional, uma empresa é avaliada como tomadora de duas grandes decisões financeiras: decisões de investimento e decisões de financiamento (ASSAF NETO, 2006).

O administrador financeiro desenvolve tarefas variadas como planejamento, concessão 
de crédito para clientes, avaliação de investimento, assim como meios de obter recursos para financiar as operações da empresa. Em anos recentes, as mudanças nos ambientes econômicos aumentaram a importância e a complexidade de suas tarefas.

A análise e o Planejamento Financeiro visam monitorar a condição financeira da empresa; avaliar a necessidade de expansão da empresa, selecionar os ativos mais rentáveis e adequados aos negócios da empresa. Cabe salientar que no processo de decisão, dois aspectos devem ser considerados: o econômico, baseado no retorno do investimento e o custo de captação e o financeiro, identificando o sincronismo entre as entradas e saídas de caixa (ASSAF NETO, 2006).

Diante da de um cenário de maior integração das economias, as empresas através de seus gestores, investidores e financiadores de capitais buscam mecanismos que permitam uma análise mais abrangente de sua situação financeira e das perspectivas do mercado, com o objetivo de garantir um retorno adequado para o capital aplicado.

Segundo Padoveze (2006, p. 233) "quando o modelo de gestão financeira é bem formatado e conduzido, aderente à cultura geral da organização os resultados tendem a ser expressivos".

Entretanto, para determinar a capacidade de geração de caixa da empresa, é necessário obter, além das demonstrações contábeis clássicas, uma demonstração que evidencie os recebimentos e pagamentos de um período específico. Buscando atender a essas necessidades dos usuários da informação contábil, para as empresas que possuem capital aberto e lançam ações no mercado, é exigida atualmente a publicação da demonstração do fluxo de caixa, pelo fato que somente as demonstrações contábeis clássicas não permitem uma análise segura da situação financeira da empresa.

De acordo com Leone (1999), as pequenas e médias empresas são caracterizadas por um nível de maturidade organizacional muito baixo. Os processos de planejamento e de controle são geralmente pouco formalizados e quantificados. Os aspectos dos controles financeiros se apresentam com estruturas simplificadas inicialmente, passando para controles mais efetivos, principalmente na área da tesouraria e, posteriormente, numa empresa mais madura, adotando controles mais efetivos de administração financeira.

$\mathrm{Na}$ perspectiva da Gestão Contábil, especificamente no aspecto financeiro de curto prazo, devemos iniciar uma reflexão pelos desafios e obstáculos que surgem à introdução de processos de inovação e mudanças nas empresas de todos os segmentos.

Segundo Matias e Lopes Jr. (2002), a administração do caixa é um ponto chave para a 
sobrevivência de uma pequena empresa. $\mathrm{O}$ Fluxo de Caixa é um instrumento de previsão, que serve para antecipar possíveis situações a serem enfrentadas pelo gestor. $\mathrm{O}$ uso contínuo desse método e os ajustes realizados conforme as oscilações do mercado e do próprio negócio irão tornar as informações cada vez mais precisas e confiáveis, tornando-se numa ferramenta muito importante na gestão dos negócios.

Apesar dessa atividade se apoiar fortemente em demonstrações financeiras baseadas em regime de competência, o objetivo que está por trás da mesma é avaliar os fluxos de caixa e desenvolver planos que assegurem fluxos de caixa adequados para dar apoio às metas da empresa. A elaboração do fluxo de caixa de uma empresa é a base principal para a sua avaliação e projeção adequadas.

Oliveira (2000) afirma que, dadas as suas características, as pequenas empresas, na sua maioria, não planejam as atividades tanto no curto como no longo prazo. Não planejam, dentre outros itens, as vendas, os estoques, as compras, as despesas e receitas, os custos, e o caixa da empresa. Por isso, tais empresas estão sempre tentando resolver os problemas quando eles aparecem, não procurando prevê-los nem se programando para evitá-los.

Neste sentido, a gestão financeira, para ser eficaz e precisa estar sustentada e orientada por um planejamento de suas disponibilidades. Para isso o gestor precisa de instrumentos confráveis que o auxiliem a maximizar os rendimentos dos excessos de caixa ou a estimar as necessidades futuras de financiamentos, para que possa tomar decisões certas e oportunas, num cenário de escassez de recursos e taxas de juros elevadas (ASSAF NETO, 2006).

$$
\begin{aligned}
& \text { "A necessidade de capital de giro (NCG) é } \\
& \text { função da atividade da empresa e varia com as } \\
& \text { vendas e com o ciclo financeiro. A necessidade } \\
& \text { de capital de giro nasce do descompasso entre } \\
& \text { contas a pagar e contas a receber. A NCG é a } \\
& \text { diferença entre os ativos e os passivos circulantes } \\
& \text { cíclicos, de origem estritamente operacional, } \\
& \text { também chamados de ativos e passivos } \\
& \text { operacionais. A NCG é muito sensivel às } \\
& \text { modificações no ambiente econômico em que a } \\
& \text { empresa opera”. (ABREU FILHO, 2008, } \\
& \text { pág. 63). }
\end{aligned}
$$

A NCG mostra qual é o capital de giro mínimo que a empresa precisa para pagar as suas dívidas de curto prazo sem recorrer a empréstimos. Em termos práticos, a NCG é obtida através da elaboração de um Fluxo de Caixa, que reflete as projeções de entradas e saídas de caixa, de forma que podemos ter uma ideia sobre a NGC antecipadamente, o que permite negociar preços e prazos com clientes e fornecedores, abrir eventuais linhas de crédito para as situações emergenciais, obtendo assim melhores taxas e reduzindo o stress na gestão do negócio.

O Fluxo de Caixa é composto por três partes básicas: fluxos operacionais (produção e venda dos produtos e serviços da empresa), 
fluxos de investimento (compra e venda de ativos e participações societárias) e fluxos de financiamento (operações de empréstimo e capital próprio). Estes três fluxos simultâneos são responsáveis pela determinação do saldo de caixa, do volume de títulos negociáveis da empresa e de sua rentabilidade (MATIAS \& LOPES JR., 2002).

Para a elaboração do Fluxo de Caixa, as premissas utilizadas precisam estar fundamentadas em diversos fatores de ordem operacional e das decisões estratégicas tomadas pela administração. Para Abreu Filho (2008), a análise dinâmica aborda o risco financeiro das empresas. Trata-se de um modelo integrado de análise que procura explicar as causas das modificações da situação financeira de uma empresa. A análise é realizada em três níveis:

a) nível operacional;

b) nível tático, relacionado ao curto prazo;

c) nível estratégico, relacionado com a alta administração da empresa;

A análise financeira dinâmica permite uma administração do capital de giro através do gerenciamento da liquidez, dos créditos de clientes, dos estoques e dos diversos passivos existentes, sendo que o administrador define a composição do ativo e do passivo, levando em consideração o risco assumido e o retorno esperado (ABREU FILHO, 2008).

Embora esta ferramenta esteja baseada na simulação de resultados (produção, venda, custos) e possam ocorrer flutuações macroeconômicas internas e externas, assim como do próprio setor de atuação, risco de mercado, acirramento da concorrência, etc.; podem trazer um resultado diverso do que foi previsto.

No entanto, a análise comparada das informações projetadas com as efetivas e realizando-se os ajustes necessários, o planejamento financeiro oferece ao administrador a possibilidade de se antecipar diante problemas futuros de caixa, custos, rentabilidade do negócio, otimizando-se assim o resultado da empresa e mantendo sua longevidade, que constitui o objetivo máximo da empresa.

O levantamento e inserção de todas as receitas e despesas relacionadas às atividades $\mathrm{da}$ empresa são fundamentais para que o Fluxo de Caixa reflita efetivamente o que ocorre na empresa, fatores contingenciais podem ser administrados através de reservas e custos como $13^{\circ}$ salário, férias entre outros, podem ser distribuídos ao longo do ano para não sobrecarregar o caixa no momento do pagamento destes itens.

Temos abaixo um modelo simples de Fluxo de Caixa diário de empresa, distribuído conforme os respectivos prazos de recebimento e pagamento, o que permite identificar o exato momento em que a empresa terá eventuais excedentes ou insuficiência de recursos, proporcionando o planejamento adequado das 
atividades: se podemos comprar a prazo ou vista com desconto, o momento adequado de comprar matéria-prima ou realizar um investimento, respeitando os ciclos de produção, operacional e financeiro, maximizando o resultado da empresa.

Tabela 1 - Modelo de Fluxo de Caixa Diário de Empresa

\begin{tabular}{|c|c|c|c|c|c|c|c|}
\hline \multirow[b]{2}{*}{ Entradas de Caixa } & \multicolumn{7}{|c|}{ Fluxo de Caixa } \\
\hline & seg_1 & ter_2 & qua_3 & qui_4 & sex_5 & seg_8 & Total \\
\hline Recebimento dos cartões crédito & $2.500,00$ & 0,00 & $4.500,00$ & $3.500,00$ & $3.800,00$ & $6.500,00$ & $20.800,00$ \\
\hline Vendas a vista cheques & & & $4.800,00$ & $4.000,00$ & $4.000,00$ & $4.000,00$ & $16.800,00$ \\
\hline Vendas a vista dinheiro & $2.400,00$ & 0,00 & $2.000,00$ & $2.000,00$ & $2.000,00$ & $4.400,00$ & $12.800,00$ \\
\hline Recebimento de cheques pré-datados & $3.500,00$ & 0,00 & 0,00 & $3.800,00$ & $3.500,00$ & $5.000,00$ & $15.800,00$ \\
\hline Resgate aplicação Financeira & & & & & $10.000,00$ & & $10.000,00$ \\
\hline Créditos em atraso & & $8.900,00$ & & & & & $8.900,00$ \\
\hline \multirow[t]{2}{*}{ Total das entradas de caixa (1) } & $8.400,00$ & $8.900,00$ & $11.300,00$ & $13.300,00$ & $23.300,00$ & $19.900,00$ & $85.100,00$ \\
\hline & seg_1 & ter_2 & qua_3 & qui_4 & sex_5 & seg_8 & \\
\hline \multicolumn{8}{|l|}{ Saídas de caixa } \\
\hline Fornecedores & $2.700,00$ & $2.500,00$ & $2.990,00$ & $2.800,00$ & $2.000,00$ & $2.700,00$ & $15.690,00$ \\
\hline Impostos e taxas & & $8.000,00$ & & & $2.500,00$ & & $10.500,00$ \\
\hline Aluguel & & & $10.000,00$ & & & & $10.000,00$ \\
\hline Folha de pagamento & & & & & $35.500,00$ & & $35.500,00$ \\
\hline Financiamento LP & & $3.500,00$ & & & & & $3.500,00$ \\
\hline Aplicação financeira & & & & & & & 0,00 \\
\hline Outras saídas de caixa & & $2.500,00$ & & & $1.900,00$ & $6.000,00$ & $10.400,00$ \\
\hline Total de saídas de caixa(2) & $2.700,00$ & $16.500,00$ & $12.990,00$ & $2.800,00$ & $41.900,00$ & $8.700,00$ & $85.590,00$ \\
\hline Saldo de caixa $3(1$ - 2) & $5.700,00$ & $-7.600,00$ & $-1.690,00$ & $10.500,00$ & $-18.600,00$ & $11.200,00$ & $-490,00$ \\
\hline Saldo inicial (4) & $15.500,00$ & $21.200,00$ & $13.600,00$ & $11.910,00$ & $22.410,00$ & $3.810,00$ & $15.010,00$ \\
\hline Saldo Final $(4+3)$ & $21.200,00$ & $13.600,00$ & $11.910,00$ & $22.410,00$ & $3.810,00$ & $15.010,00$ & \\
\hline
\end{tabular}

Fonte: Elaborado pelos autores.

O fluxo de caixa detalhado permite a identificação de pontos críticos ou ajustes necessários nas operações da empresa, com reflexos sobre o caixa da empresa. De acordo com os dados da tabela 1 , podemos perceber que os recebimentos das vendas por meio dos cartões de crédito, representam 24,4\% das entradas de caixa da empresa requerem um prazo de recebimento de no mínimo trinta dias.

Neste caso, o gestor poderia incentivar descontos para pagamentos à vista, para antecipar a receita. Nas saídas, podemos ver que a folha de pagamentos representa um ônus de 40,9\% das saídas de caixa, eventualmente este valor poderia ser desmembrado em duas parcelas: adiantamento e saldo, reduzindo o impacto deste no fluxo de caixa. Estas propostas constituem alguns exemplos de estratégias que podem ser adotadas ao se analisar um fluxo de caixa projetado, o que permite se antecipar a eventuais problemas ou falta de recursos, racionalizando o processo. 


\section{Metodologia}

Esta pesquisa visa analisar o perfil da gestão financeira das empresas que participaram do Projeto PEIEX do núcleo SP entre 2010 e 2012. Para tanto, foi realizada uma pesquisa aplicada, qualitativa, documental, baseando-se nos formulários preenchidos pelas próprias empresas e extensionistas e também nas entrevistas realizadas nas próprias empresas e nos treinamentos realizados.

Esta análise admite tanto abordagens quantitativas quanto qualitativas, pois não são mutuamente excludentes, elas podem ser utilizados de forma complementar. Presta-se tanto aos fins exploratórios quanto ao de verificação, confirmando ou não hipóteses ou suposições preestabelecidas. A análise de conteúdo é composta por três etapas: a) a análise preliminar, b) a exploração do material, c) tratamento dos dados e interpretação (VERGARA, 2010).

Trata-se ainda de uma pesquisa investigativa explicativa, uma vez que busca identificar os fatores que determinam ou que contribuem para a ocorrência dos fenômenos (GIL, 2006). A investigação explicativa tem como principal objetivo tornar algo inteligível, justificar os motivos. Segundo Vergara (2010) visa, portanto, esclarecer quais fatores contribui de alguma forma, para a ocorrência de determinado fenômeno, tentando elucidá-lo através dos indicadores e informações coletadas.
Obtidos os resultados, cabe ao pesquisador retornar às suposições formuladas e confirmá-las ou não, apresentando as devidas explicações.

\section{1- Delimitação da Pesquisa}

O campo de estudo foi as PME's industriais atendidas pelo Projeto PEIEX Núcleo Operacional São Paulo. O universo da pesquisa é composto por 140 empresas de diversas de setores, sendo que $71 \%$ delas enquadram-se como empresas de pequeno porte, entre 01 e 19 funcionários.

\section{2- Estratégia de Coleta de Dados e Instrumento de Pesquisa.}

Os autores tiveram acesso ao banco de dados do NO São Paulo do PEIEX, onde foram analisadas as fichas de informações de cada da empresa, que informa dados relacionados à estrutura de produção, mão-de-obra, técnicas relacionadas à qualidade e produtividade, participação em eventos e associações; e o questionário check list aplicado em todas as empresas, que constitui um levantamento de 249 itens que contemplam todas as áreas funcionais para identificar o grau de competitividade que a empresa se encontra, de forma que por meio de uma escala de três itens, verificam-se então o nível de gestão que a empresa pratica, assinalando "S" para sim, ela pratica esta atividade; assinalando " $\mathrm{N}$ ” para não, ela não pratica a atividade; e ainda assinalando $\mathrm{P}$, para as atividades que praticam parcialmente. 
Posteriormente, através do levantamento de informações coletadas nas visitas "in loco" dos técnicos extensionistas e também das entrevistas realizadas com os empresários, é elaborado um diagnóstico de cada empresa, detalhando como a empresa está estruturada, os pontos críticos e os pontos positivos evidenciados em cada setor, indicando as capacitações e as melhorias necessárias para aperfeiçoar a gestão, no qual foram concentradas as análises.

De posse deste relatório, o empresário define as prioridades de atendimento, que poderiam ser implantadas pela equipe de extensionistas ou terceirizadas para entidades parceiras de oferta de ações gerenciais ou tecnológicas.

A fase de capacitação e de implantação das melhorias priorizadas pelo empresário consiste o ponto central das ações do projeto. As ações consistiram em assessoria técnica e gerencial, capacitação técnico-econômica e gerencial, assessoria na organização de redes de cooperação e apoio na reorganização de estruturas e processos organizacionais.

A ficha de avaliação do projeto e a ficha de evolução da empresa constituem a última fase do projeto. Esta avaliação é feita pelo empresário, opinando sobre o atendimento recebido, os eventuais reflexos ocorridos na gestão e nos resultados da empresa, expressando seu grau de satisfação com o trabalho desenvolvido.

Para a implantação do Projeto de Extensão Industrial Exportadora - PEIEX, da APEX Brasil em parceria com o Núcleo de Negócios Afro-Étnicos Zumbi dos Palmares, Núcleo Operacional São Paulo, foram utilizados oito profissionais: um coordenador, um monitor e quatro técnicos de nível superior e pósgraduados em diversas áreas, e, dois estagiários graduandos em administração.

\section{Resultados - Análise Geral dos Dados / Indicadores}

Com base no banco de dados do Projeto PEIEX Núcleo Operacional São Paulo, na tabela 1, verificou-se que das 140 empresas atendidas, existe uma maior concentração de adesões na área de confecções, produtos médico-hospitalares e plásticos e polímeros, representando $40 \%$ do total, outra parte ficou pulverizada nos setores de artesanato, construção civil, gráficas e de cosméticos; atingindo um total de $28,57 \%$, total acumulado de $68,57 \%$ e outros setores que tiveram uma menor participação relativa, compondo os $31,43 \%$ complementares. 
Tabela 2 - Classificação das empresas atendidas por ramo de atividade

\begin{tabular}{|l|c|c|}
\hline Ramos de Atividade & $\begin{array}{c}\text { Número de } \\
\text { Empresas }\end{array}$ & $\begin{array}{c}\text { Total } \\
\text { Geral (\%) }\end{array}$ \\
\hline Confecções & 25 & 17,86 \\
\hline Médico-Hospitalares & 17 & 12,14 \\
\hline Plásticos e Polímeros & 14 & 10,01 \\
\hline Artesanato & 10 & 7,14 \\
\hline Construção Civil & 10 & 7,14 \\
\hline Gráficas & 10 & 7,14 \\
\hline Cosméticos & 10 & 7,14 \\
\hline Outros & 44 & 31,43 \\
\hline Total & $\mathbf{1 4 0}$ & $\mathbf{1 0 0}$ \\
\hline
\end{tabular}

Fonte: Banco de Dados extraídos do Projeto PEIEX NO SP, atendidas entre 2010 e 2012.

Apesar de constatarmos uma diversidade razoável de empresas agrupadas por setores, porém elas possuem um perfil bastante parecido pelo critério de número de funcionários (classificação MDIC): 71\% (1 - 19), 22\% (2099), $6 \%$ (100-199) e $1 \%$ acima de 500 funcionários; sendo assim, utilizaremos a amostra integral, ou seja, as 140 empresas, num período de 16 meses, entre 2010 e 2012, para analisar o grau de utilização do planejamento financeiro na estratégia de gerenciamento do negócio.

$\mathrm{Na}$ tabela abaixo, conforme levantamento dos diagnósticos individuais das empresas atendidas, podemos identificar as principais demandas: Finanças e Custos (63,6\%), Administração Estratégica (60,0\%), Vendas e Marketing (52,1\%), Comércio Exterior, (40,7\%).
Tabela 3 - Tipos de Demanda x Necessidades

Diagnosticadas nas Empresas

\begin{tabular}{|c|c|c|}
\hline Tipo de Demanda & $\begin{array}{c}\text { Número de } \\
\text { Empresas }\end{array}$ & $\begin{array}{c}\text { Total } \\
\text { Geral (\%) }\end{array}$ \\
\hline $\begin{array}{c}\text { Administração } \\
\text { Estratégica }\end{array}$ & 84 & 60,0 \\
\hline Capital Humano & 22 & 15,7 \\
\hline Finanças e Custos & 89 & 63,6 \\
\hline Vendas e Marketing & 73 & 52,1 \\
\hline Comércio Exterior & 57 & 40,7 \\
\hline Produtos e & 24 & 17,1 \\
\hline Manufaturas & & \\
\hline
\end{tabular}

Fonte: Banco de Dados extraídos do Projeto PEIEX

NO SP, atendidas entre 2010 e 2012.

De acordo com a tabela 3, cabe salientar, que no caso do Comércio Exterior, que obteve $40,7 \%$ de demanda, avaliou-se o interesse da empresa em conhecer mais o segmento, independente de seu porte e da aderência de seu produto para o mercado externo, justificando assim o elevado número de empresas que se manifestaram positivamente para participarem das capacitações relacionadas ao comércio exterior e conhecer os diversos programas da Apex Brasil para incrementar as exportações brasileiras.

Por outro lado, uma mesma empresa pode apresentar uma única demanda, ou várias delas, em áreas diferentes, podendo priorizar qual ou quais serão trabalhadas inicialmente. Depois de definido qual demanda será atendida, é oferecida capacitação realizada no núcleo pelos próprios técnicos extensionistas ou direcionada para entidades parceiras.

Pode-se verificar a inter-relação entre Administração Estratégica e Finanças e Custos, 
respectivamente $60 \%$ e $63,6 \%$ das demandas, ambas relacionadas ao planejamento e definição de estratégias de participação no mercado, marketing, nicho atuação, linha de produtos, etc., que mostra que muitas empresas iniciam o seu negócio sem ter um plano de ação consistente, envolvendo todos os aspectos.

Mais especificamente com relação às demandas de Finanças e Custos, que consiste em nosso objetivo central da pesquisa, o check-list da empresa aborda os seguintes aspectos: Administração Financeira e Indicadores Financeiros e Administração de Custos e Indicadores de Custos, através de uma série de sub-itens, questionando se empresa adota diversos tipos procedimentos, sim ou não e eventualmente de forma parcial.

Se houve uma demanda de Finanças e Custos de 63,6\%, significa que apenas 36,4\% das empresas exercem efetivamente um controle adequado da área, utilizando como ferramentas um fluxo de caixa para gerenciamento das entradas e saída de recursos, análise da margem de contribuição e da margem de lucro, definição de preços levando em consideração os custos de produção e a concorrência, utiliza a projeção de resultados como forma de antecipar-se a problemas futuros, etc.

Deste percentual de 63,6\%, temos uma amplitude muito grande entre os participantes: desde aqueles que não sabiam como ia seria a situação do caixa do dia seguinte, se o preço do produto cobria os custos de produção, até aqueles que tinham um controle incipiente ou parcial de sua área financeira e precisava rever ou atualizar os critérios, as planilhas, pois a empresa cresceu, diversificou seus produtos e o empresário perdeu o controle do negócio.

$\mathrm{Na}$ medida em que a empresa não cria indicadores para acompanhar seu padrão de qualidade, eficiência, ou metas e objetivos a serem atingidos, dificilmente elevará seu patamar de gestão e resultados, pois não tem a base de comparação, não pode identificar os aspectos que possam ter influenciado negativamente estes indicadores e consequentemente como melhorálos.

Nas capacitações realizadas, focadas em planejamento financeiro, formação de preços e custos, apresentação de opções de fontes de financiamento, para atender esta demanda, a participação média dos empresários foi de apenas 30\%. Os treinamentos foram realizados durante a semana em horário comercial, optouse posteriormente em realizá-los aos sábados, mas não houve aumento significativo de participantes.

Apesar das dificuldades de deslocamento existentes na cidade de São Paulo e pelo fato de muitos empresários atuarem em diversas frentes, produção, vendas, inclusive o financeiro, não se justifica o baixo índice de adesão, uma vez que os diagnósticos já identificaram os problemas centrais cada gestão e estes treinamentos os 
ajudariam a iniciar um processo de melhoria contínua que poderia alavancar o seu negócio. $\mathrm{O}$ tempo "perdido" no entendimento e no planejamento das operações da empresa é fundamental para o seu sucesso.

Cabe salientar que o Projeto PEIEX não representa custo financeiro para a empresa, mas sim de compromisso e dedicação de parte de seu tempo para o atendimento dos técnicos, realização dos treinamentos e colocar as ferramentas apresentadas em prática. $\mathrm{O}$ projeto Também realiza missões internacionais e seminários de cultura exportadora, sempre visando a qualificação das empresas em áreas como negociação, planejamento estratégico, marketing e vendas.

\section{Considerações Finais}

O presente trabalho teve como objetivo geral identificar o perfil da gestão financeira e a adoção de técnicas de planejamento financeiro da empresarial em micro, pequenos e médios empreendimentos industriais atendidos pelo Núcleo Operacional - SP.

Através da análise de dados, entre as 140 empresas atendidas pelo Projeto PEIEX, foi possível identificar que apenas 36,4\% aplicam adequadamente as ferramentas de planejamento, acompanhamento e controle das finanças da empresa, e, enquanto $63,6 \%$ das empresas atendidas utilizam parcialmente ou de forma incipiente as ferramentas, mostrando um nível baixo de adoção de aplicação do fluxo de caixa e orçamento empresarial e controle adequado de custos.

Como foi analisado anteriormente, a identificação da NCG da empresa pode ser obtida através da utilização do Fluxo de Caixa, que permite o controle adequado das receitas e despesas, identifica eventuais gargalos ou excedente de recursos e possibilita o planejamento adequado das atividades, respeitando os ciclos de produção, operacional e financeiro da empresa.

Através do uso adequado do fluxo de Caixa, o empresário reduz o custo financeiro decorrente da má gestão dos recursos financeiros, melhora a margem de lucro e possibilita uma visão de curto e médio prazo do negócio, identificados pontos críticos e realizando eventuais ajustes, salientando que a qualidade das informações é fundamental para o sucesso da ferramenta como fonte de apoio ao gestor.

Nas visitas realizadas às empresas e também na discussão realizada nos treinamentos, a alegação maior dos empresários é a falta de tempo para alimentar a planilha do fluxo de caixa própria ou fornecida pelo núcleo. Muitas destas empresas recebiam o balancete da contabilidade bem depois dos fatos terem ocorrido, o que impossibilitava a correção de rumos, e, muitos não sabiam como "ler" as informações ou simplesmente não as tinham 
para analisar e utilizar como ferramenta de planejamento e gestão.

Embora o sucesso da empresa não se restrinja apenas ao aspecto financeiro, o desequilíbrio reflete a falta de coordenação e planejamento entre os setores de vendas, produção, custos e fontes de financiamento das operações, criando um efeito de looping de difícil identificação onde o problema foi gerado inicialmente. Como as taxas de juros de uma forma geral são elevadas no Brasil, apesar da queda da Taxa Selic e da ampliação do volume de crédito, principalmente pelos bancos públicos, parte de seu eventual lucro é absorvido pelos custos financeiros, em função $\mathrm{da}$ necessidade de financiamento do NCG.

Além destes problemas, identificou-se uma baixa adesão aos treinamentos oferecidos pelo Núcleo SP do PEIEX, que poderiam atenuar parte dos problemas, através $\mathrm{da}$ capacitação dos envolvidos e melhoria dos controles e indicadores financeiros. Este fato também ocorreu em outros estados onde é oferecido o Projeto PEIEX.

A pesquisa procurou discutir o perfil de gestão financeira adotada pelas empresas atendidas pelo Projeto PEIEX, contribuiu para um maior conhecimento da estrutura e das necessidades das empresas atendidas, através da identificação das demandas e das capacitações realizadas, podemos concluir que ainda é incipiente a adoção do Fluxo de Caixa e outras ferramentas de controle como apoio na gestão das empresas. Embora tenhamos no universo de 140 empresas atendidas, algumas que fazem adequadamente o dever de casa, algumas de maneira superficial, outras procurando absorver os conceitos abordados e colocá-los em prática, ainda existe muito a ser feito para termos em nossas empresas um modelo de gestão mais eficiente, dando suporte para os empresários superar os desafios que são cada vez maiores na economia globalizada.

\section{Referências bibliográficas}

ABREU FILHO, J.C.F. Finanças Corporativas. $10^{\mathrm{a}}$ ed., Rio de Janeiro: Ed. FGV, 2008.

ASSAF NETO, A. Finanças Corporativas e Valor. $2^{a}$ ed. São Paulo: Atlas, 2006.

CERVO, Amado Luiz. Metodologia

Científica. São Paulo: Prentice Hall, 2002.

FILARDI, L. F. Estudo dos fatores contribuintes para a mortalidade precoce de pequenas empresas da cidade de São Paulo. Tese (doutorado), Universidade de São Paulo, São Paulo, 2006. Disponível em: $<$ http://www.teses.usp.br/teses/disponiveis/ 12/12139/tde-20112006-093303/pt-br.php> Acessado em: 14 nov. 2011 
GIL, A. C. Como elaborar projetos de pesquisa. $4^{a}$ ed. São Paulo: Atlas, 2010.

\section{GLOBAL ENTREPRENEURSHIP}

MONITOR - GEM. Global Reports, Babson

College Press, 2009. Disponível em: <http://www.gemconsortium.org/

about.aspx?page=pub_gem_global_reports.>

Acessado em: 07 nov. 2013

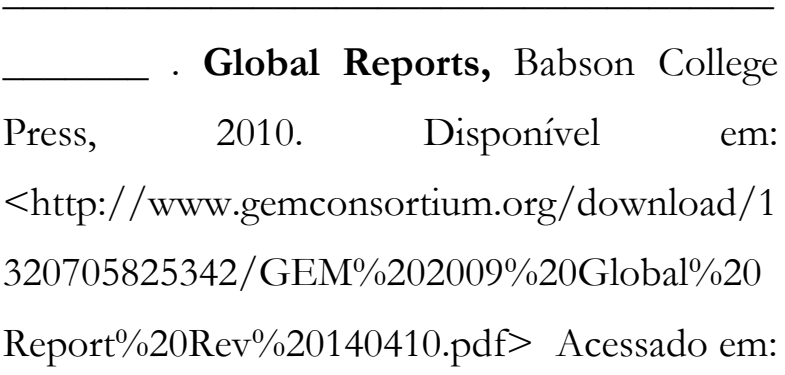
18 out. 2013.

GITMAN, L.J. Princípios de Administração

Financeira. $2^{\mathrm{a}}$ ed. Porto Alegre: Bookmam, 2001.

GRECO, S. M. S. S. et al. Empreendedorismo no Brasil: 2010. Curitiba: IBQP, 2010.

Disponível em:

<http://www.gemconsortium.org/

document.aspx?id=1130. $>$ Acessado em: 06 nov. 2013.

LEONE, Nilda Maria Guerra. As

especificidades das pequenas e médias

empresas. São Paulo: Revista de

Administração da Universidade de São Paulo, v. 34, n² 2, abril/junho, 1999.

LUCATO W. C \& VIEIRA JR M. As dificuldades de Capitalização das pequenas e médias empresas brasileiras. Produção, v. 16, n. 1, p. 024-033, Jan./Abr. 2006.

MATIAS, A.B. \& LOPES JR., F. Administração Financeira nas Empresas de Pequeno Porte. São Paulo: Manole, 2002.

OLIVEIRA, A. G. et aI. A utilização das informações geradas pelo sistema de informação contábil como subsídio aos processos administrativos nas pequenas empresas. Curitiba: Revista da FAE, v. 3, n 3, setembro/dezembro, 2000.

PADOVEZE, C. L. Administração financeira de empresas. São Paulo: Thomson Learning, 2006.

PEIEX Projeto Extensão Industrial Exportadora. Manual de Trabalho. Apex Brasil, 2011

SERVIÇO BRASILEIRO DE APOIO ÀS MICRO E PEQUENAS EMPRESAS SÃO PAULO - SEBRAE - SP. Doze anos de monitoramento da sobrevivência e mortalidade de empresas, 2010. Disponível em:

$<$ http://www.sebraesp.com.br/QueroAbrirUm aEmpresa/Biblioteca/OutrosConteudos/Estud os $<$ Pesquisas/MortalidadeDasEmpresas/Pagin as/MortalidadeDasEmpresas.aspx.> Acessado em: 15 out. 2013.

Sobrevivência e Mortalidade de Empresas, 2008.

Disponível

em: 
$<$ http://www.sebraesp.com.br/QueroAbrirUm aEmpresa/

Biblioteca/OutrosConteudos/EstudosEPesquis as/MortalidadeDasEmpresas/Paginas/Mortalid adeDasEmpresas.aspx > Acessado em: 18 out. 2013.

SERVIÇO BRASILEIRO DE APOIO ÀS MICRO E PEQUENAS EMPRESAS SÃO PAULO - SEBRAE - Nacional. Características do empreendedor. Disponível em: <http://www.sebrae.com.br/momento/oque-o-sebrae-pode-fazer-por-mim/ integra_bia?ident_unico=336> Acessado em: 14 nov. 2013.

SILVA, J. U. Gestão das Relações Econômicas Internacionais e Comércio Exterior. São Paulo, 2008.

VERGara, S. C. Métodos de Pesquisa em

Administração. $4^{a}$ ed. São Paulo: Atlas, 2010.

188 MESSIAS, J.F; SILVA, J.U.; ROSSINI, A.M.: Perfil Da Gestão Financeira Das Empresas Industriais Atendidas Pelo Peiex Núcleo São Paulo/SP Entre 2010 - 2012. 